\title{
Use of the rendezvous technique to treat a nonhealing biliary cutaneous fistula
}

A 32-year-old man with a history of gunshot wound to the liver was referred for management of a biliocutaneous fistula. Previously, a biloma had been drained percutaneously and an endoscopic retrograde cholangiogram (ERC) demonstrated a bile leak, which was treated with a stent. The fistula persisted despite three additional stent changes.

On presentation, a percutaneous fistulogram revealed communication with a peripheral right posterior bile duct ending in a large biloma. The remainder of the biliary tree was not visualized ( Fig. 1). A catheter was advanced over a guide wire through the sinus tract and into the right posterior duct. No communication was initially seen between the right posterior hepatic bile ducts and the remainder of the biliary system ( Fig. 2 ); however, the wire was eventually passed through the common hepatic duct and into the duodenum ( Fig.3). ERC then demonstrated a severe stricture at the origin of the left hepatic duct with anomalous drainage of the right posterior duct arising from the left main hepatic duct ( Fig.4). The left main hepatic duct stenosis was traversed, dilated, and stented. The guide wire placed percutaneously was grasped with a snare and pulled through the duodenoscope. A second biliary stent was placed into the right posterior duct. The right anterior duct had not been injured ( $\bullet$ Fig.5). Immediately following the procedure, drainage from the fistula ceased. Follow-up at 125 days demonstrated complete closure of the fistula and the stents were removed.

Rendezvous procedures are combined endoscopic and percutaneous techniques, which facilitate the establishment of intra- and extrahepatic biliary access. These procedures have been used to restore anatomic drainage in cases where retrograde and/or transhepatic access has failed. Several earlier reports have described use of the rendezvous procedure to treat posttransplant biliary strictures [1], complete transection of the common bile duct [2], and bile leaks [3].

This is the first report of successful closure of a biliocutaneous fistula using a rendezvous technique. Treatment with endoscopic stents alone failed due to inability

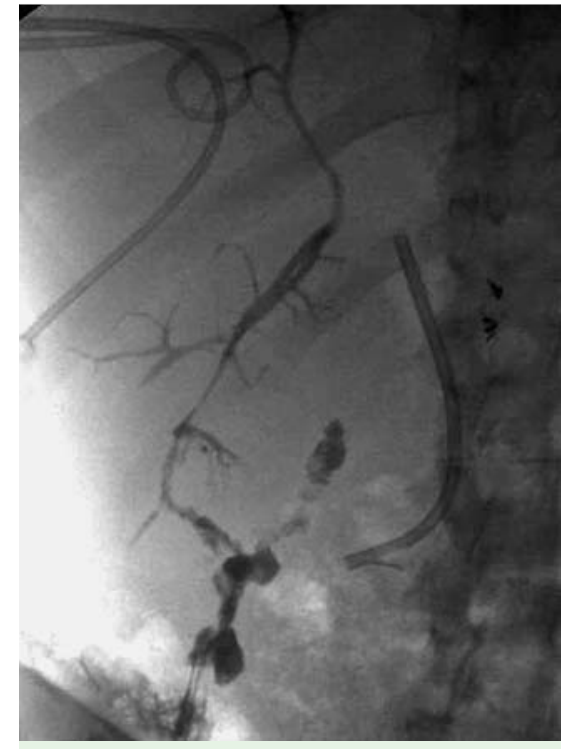

Fig. 1 Opacification of an irregular biloma communicating with the right posterior hepatic ducts.

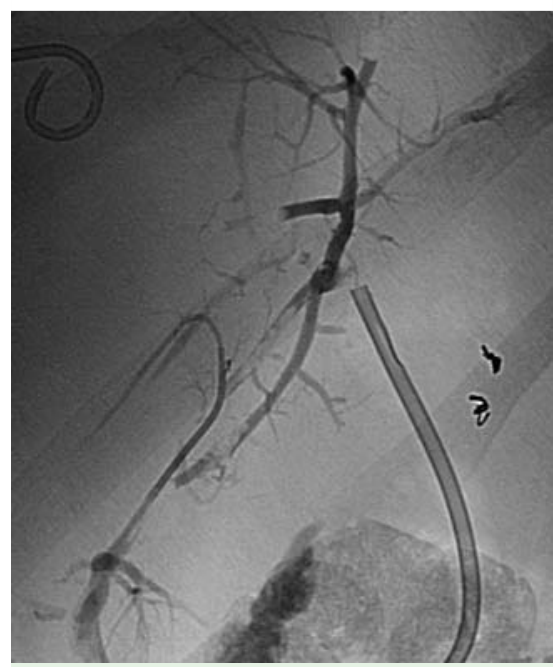

Fig. 2 Contrast injection reveals no communication between the right posterior hepatic bile ducts and the remainder of the biliary system.

to identify and treat aberrant drainage of the right posterior segment and the presence of a stricture of the left duct. In this case, the ability to restore biliary continuity and divert biliary flow through the papilla led to closure of the fistula, avoiding major surgery.

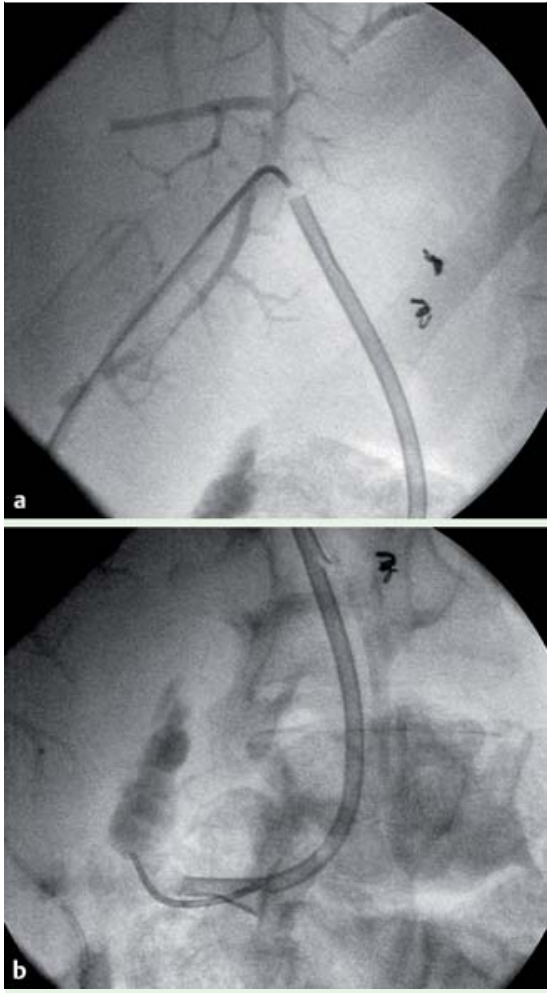

Fig.3 Guide wire and catheter advanced into the common hepatic duct (a), and then into the bowel (b).

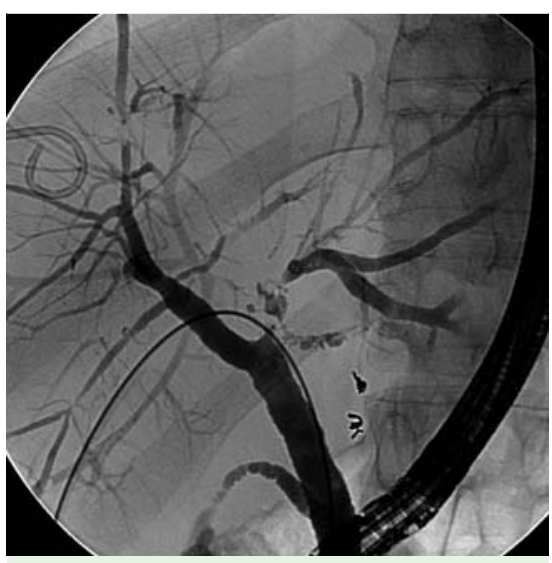

Fig.4 A severe irregular stricture seen at the origin of the left hepatic duct with associated debris and anomalous anatomy with the right posterior hepatic duct arising from the left main hepatic duct.

Endoscopy_UCTN_Code_TTT_1AR_2AG

Competing interests: None 


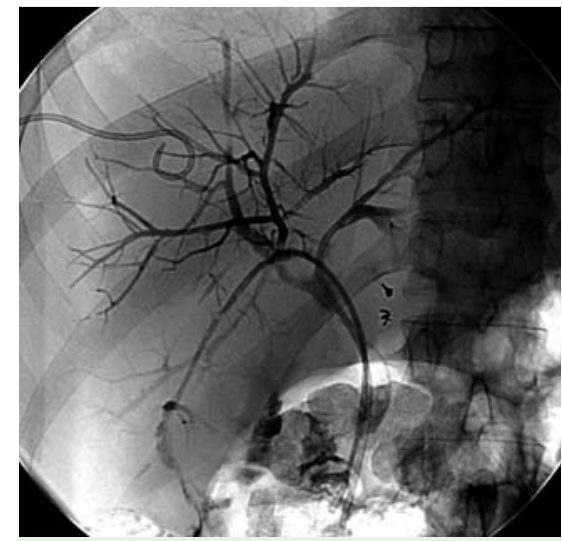

Fig. 5 Two biliary stents draining the left and right posterior ductal system with no biliary leak.

\section{J. Y. Nasr ${ }^{1}$, P. Orons ${ }^{2}$, A. Slivka'}

${ }^{1}$ Department of Gastroenterology, Hepatology, and Nutrition, University of Pittsburgh Medical Center, Pittsburgh, Pennsylvania, USA

${ }^{2}$ Department of Radiology, Division of Vascular and Interventional Radiology, University of Pittsburgh Medical Center, Pittsburgh, Pennsylvania, USA

\section{References}

1 Chang JH, Lee IS, Chun HJ et al. Usefulness of the rendezvous technique for biliary stricture after adult right-lobe living-donor liver transplantation with duct-to-duct anastomosis. Gut Liver 2010; 4: 68 - 75

2 Saleem A, Leroy AJ, Baron TH. Modified rendezvous technique with successful reconnection of completely transected common bile duct using combined endoscopic and radiologic approach. Endoscopy 2010; 42: (Suppl. 02): E178-179

3 Aytekin C, Boyvat F, Yimaz $U$ et al. Use of the rendezvous technique in the treatment of biliary anastomotic disruption in a liver transplant recipient. Liver Transpl 2006; 12: $1423-1426$

\section{Bibliography}

Dol http://dx.doi.org/

10.1055/s-0031-1291607

Endoscopy 2012; 44: E149-E150

(c) Georg Thieme Verlag KG

Stuttgart · New York

ISSN 0013-726X

\section{Corresponding author}

\section{J. Y. Nasr, MD}

Department of Gastroenterology, Hepatology, and Nutrition

University of Pittsburgh Medical Center 200 Lothrop Street

Pittsburgh

PA 15213

USA

Fax: +1-412-647-6038

nasrjy@upmc.edu 